\title{
Empirical Validation of the Global Entrepreneurship Monitor Conceptual Framework in Spanish New Technology-Based Firms
}

\author{
M. Serrano, M. Sc. ${ }^{1}$, G. Morales-Alonso, $\mathrm{PhD}^{1}$, Y. Núñez, $\mathrm{PhD}^{1}$, and J.A. Blanco-Serrano, M.Sc. ${ }^{1}$ \\ 1ETSI Industriales, Universidad Politécnica de Madrid, misd87@gmail.com; gustavo.morales@upm.es; ym.nunez@upm.es; \\ joseantonio.blanco@upm.es
}

\begin{abstract}
This study validates empirically the components of the Global Entrepreneurship Monitor Conceptual Framework (GEMCF) related (1) to the educational background of the entrepreneur, (2) the society's perception of entrepreneurship and (3) the individual's perceived capabilities. These factors' ability to explain entrepreneurship within a specific entrepreneurial ecosystem (New Technology-Based Firms, NTBF) is sought after. A structured methodology is designed, including the definition of components of the model to be validated, definition of observed variables of those components, data collection through surveys, and analyses of the data. In particular, Exploratory Factor Analysis for validation of chosen observed variables, Structural Equation Modelling (SEM) for validation of correlation among components (using Confirmatory Factor Analysis) and validation of causal relationships between components and entrepreneurship (using Structural Modelling) as proposed by the GEMCF have been used. Results obtained prove the robustness of the GEMCF.

Keywords-- Determinants of Entrepreneurship. Economic Development, Self-Employment, Confirmatory Factor Analysis (CFA), Structural Equation Modelling (SEM)
\end{abstract}

\section{INTRODUCTION}

Entrepreneurship is "at the heart of national advantage" [1] that is, it influences economic growth and development. It can be defined as the act of creating a temporary organization in search of a scalable, repeatable, profitable business model [2]. Not in vain, start-ups have been cited as the best companies for transforming innovative ideas into commercial products [3]. For this reason, it is of the greatest importance to understand what are the detonators of entrepreneurial activity. For instance, it is still pending to be answered if the individual factors are predominant over social factors or vice versa.

An important body of the entrepreneurship literature has focused on entrepreneurial intentions, as they are believed to play a crucial role on the decision to start a new firm [4]. In this domain, both individual and contextual factors have been sought after [5], usually taking the Theory of Planned Behavior as a framework [6]. Among the different contributions on this topic, some have focused on the importance of positive and negative role models [7], and on the perception of barriers for entrepreneurship [8] [9].
Nevertheless, behaviours and intentions are different constructs. That is, entrepreneurial intentions may or may not evolve in entrepreneurial behaviours.

When it comes to entrepreneurial behaviours, the Global Entrepreneurship Monitor project (GEM) is an inevitable reference. The GEM is an organisation with global recognition, and its conceptual framework has been revised year after year by entrepreneurship specialists from all around the globe, since 1999. Furthermore, the GEM is the only organization that measures entrepreneurship worldwide with a consistent methodology. They rely on the definition of the Total Early-Stage Entrepreneurial Activity (TEA), which is calculated by surveying a sample between 18 and 64 years old. The TEA is the ratio of individuals in the mentioned age range who are actively involved in business start-ups (companies spanning 0-42 months of age). That is, the TEA is a measure of concrete entrepreneurial aspiration of a society.

Last, does every type of entrepreneurship have the same relevance and the same impact on economy? Certainly, it does not. Evidence found in the literature probes that more might not be better. For example, entrepreneurship can have a negative impact in job creation since not all ventures get to become established businesses [10].

High-growth potential entrepreneurship generates economic growth. It has four main characteristics: high growth level of job creation, innovation and internationalization, and opportunity-driven motivation [11].

New Technology-Based Firms (NTBF) are likely to be high-growth potential because they are inherently innovative, usually seeking to exploit a business opportunity, easy to internationalize through Internet and online platforms, and, as a result of all these, with high potential of job creation.

The present study aims to check the validity of the GEMCF for a particular setting: the NTBF from Spain. Therefore, the research question of this paper is:

"Is the conceptual framework developed by GEM reliable when applied on existing New Technology-Based Firms?"

Digital Object Identifier (DOI):

http://dx.doi.org/10.18687/LACCEI2019.1.1.319

ISBN: 978-0-9993443-6-1 ISSN: 2414-6390

$17^{\text {th }}$ LACCEI International Multi-Conference for Engineering, Education, and Technology: "Industry, Innovation, And Infrastructure for Sustainable Cities and Communities”, 24-26 July 2019, Jamaica. 


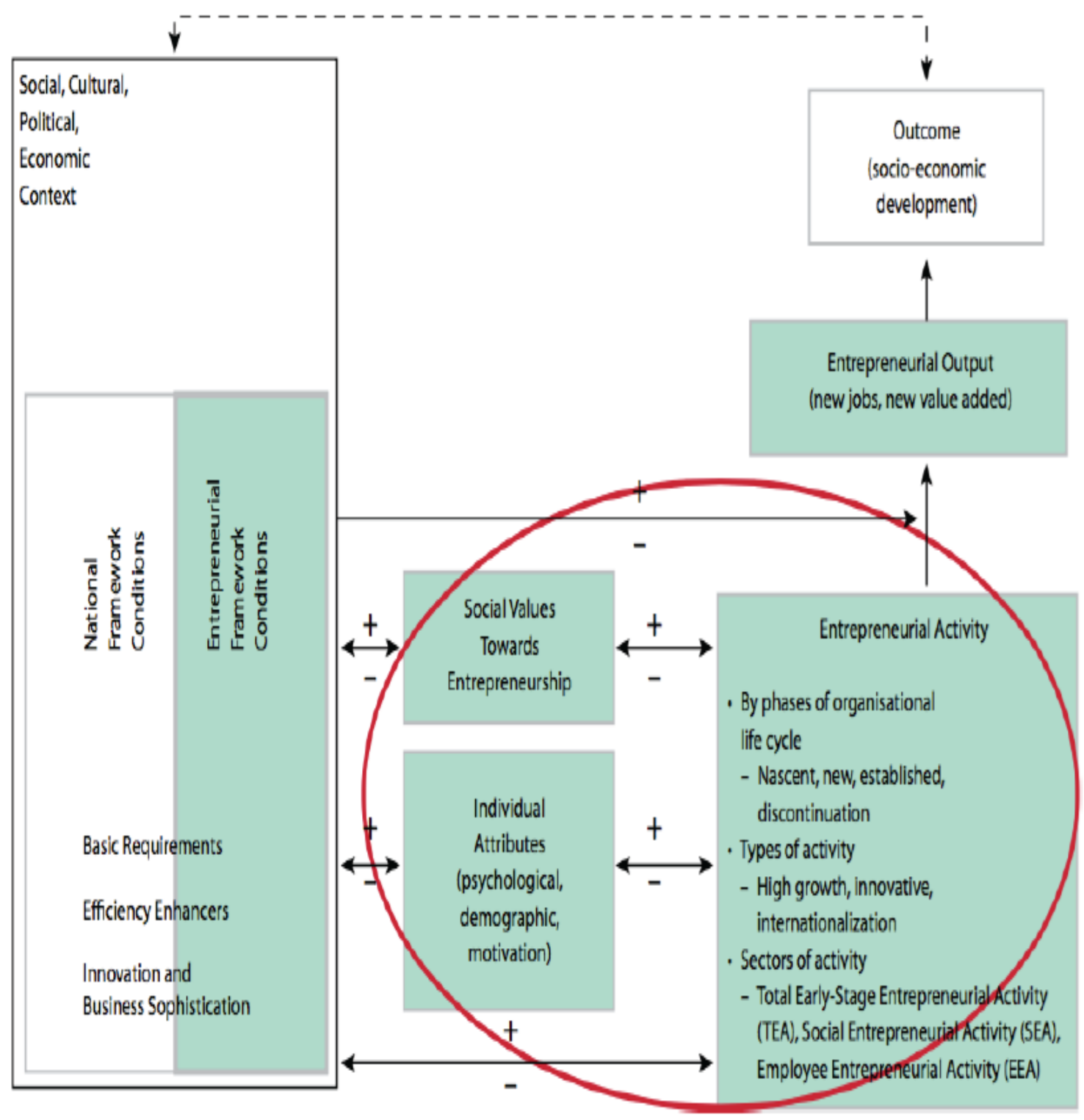

Fig. 1 Conceptual Framework of GEM (Singer et al. 2015)

\section{LITERATURE REVIEW}

Figure 1 presents the conceptual framework for entrepreneurship proposed by GEM [11]. As it can be seen, economic context effects on the Entrepreneurial Activity variable through both the Social Values and Individual Attributes factors.

The Economic Context can be identified with the economic and contextual factors that arise from the environment and act fostering or hindering entrepreneurial activities [12], [13], [14]. Recent research link poor institutional support [15] and presence of bad economic perspectives [16], with low values of entrepreneurial activity.

However, economic context alone is not a good predictor of entrepreneurial activities. In fact, entrepreneurial rates are relatively high in countries with low GDP per capita, while they are lower for countries with an intermediate level of GDP per capita. In a small set of countries with high GDP per capita, entrepreneurial level is high. This event has been

$17^{\text {th }}$ LACCEI International Multi-Conference for Engineering, Education, and Technology: "Industry, Innovation, And Infrastructure for Sustainable Cities and Communities", 24-26 July 2019, Jamaica. 
represented by a U-shaped plot that links economic development with entrepreneurial activity by [17]. The underlying reason for this relation is that the difficulties in finding jobs in developing economies suggest individuals to pursue the creation of a new venture, not due to the identification of a business opportunity, but as a mean of selfemployment.

Previous research in this field suggests that developing countries should not promote or foster the creation of new business, or at least it should not be their priority. They need to reach a higher level of economic development through investment in the skills of their population and the growth of established business, in order to achieve scale economies and efficiency. Once this level is achieved, such as in developed countries, policy makers should recognize the two ends of the entrepreneurial spectrum, namely, solo self-employment and innovative entrepreneurship, and design tailored policies. In this way, the country will obtain the maximum benefit of entrepreneurship.

If Economic Context alone does not predict levels of entrepreneurial activity, there should be some individual factors that are relevant. Among them, the exposure to positive and negative role models have been mentioned [7]. In particular, successful entrepreneurs are known to act as positive role models, thus fostering entrepreneurship, with civil servants or unsuccessful entrepreneurs act as negative role models. [8], [9].

Considering all the above-mentioned determinants and components, the following model was proposed, called "the detailed GEMCF"

In Figure 2 all the ellipses represent latent variables: they cannot be directly measured, because they are not directly observable. They need to be measured through an observed variable. For example, higher education and training could be measured in terms the maximum level of education achieved by the entrepreneurs or in terms of entrepreneurial education received. Perceived capabilities could be measured through a personality test. There are an unlimited number of alternatives to measure the components of the GEMCF.

Figure 2 also depicts one of the assumptions of the GEMCF: entrepreneurship is an output of the interrelation between individual attributes and the national context. That is why there are three single-headed arrows that link "Social, Cultural, Political and Economic Context", "Social Values towards entrepreneurship" and "Individual Attributes" with "Entrepreneurial Activity". There are also correlations among these three determinants, except between "Social Values towards entrepreneurship" and "Individual Attributes".

The aim is to test the GEMCF in a particular context and probe that the proposed determinants do explain the entrepreneurial activity, and that the proposed relationships actually exist. As seen in Figure 2 the GEMCF comprises a considerable number of components.

This research considered components that were considered easier to measure, without compromising the relevance of the research, namely, "High education and training", "Desirable career choice" and "Perceived capabilities", which are aligned with the ones proposed in the thesis objective.

$17^{\text {th }}$ LACCEI International Multi-Conference for Engineering, Education, and Technology: "Industry, Innovation, And Infrastructure for Sustainable Cities and Communities", 24-26 July 2019, Jamaica. 


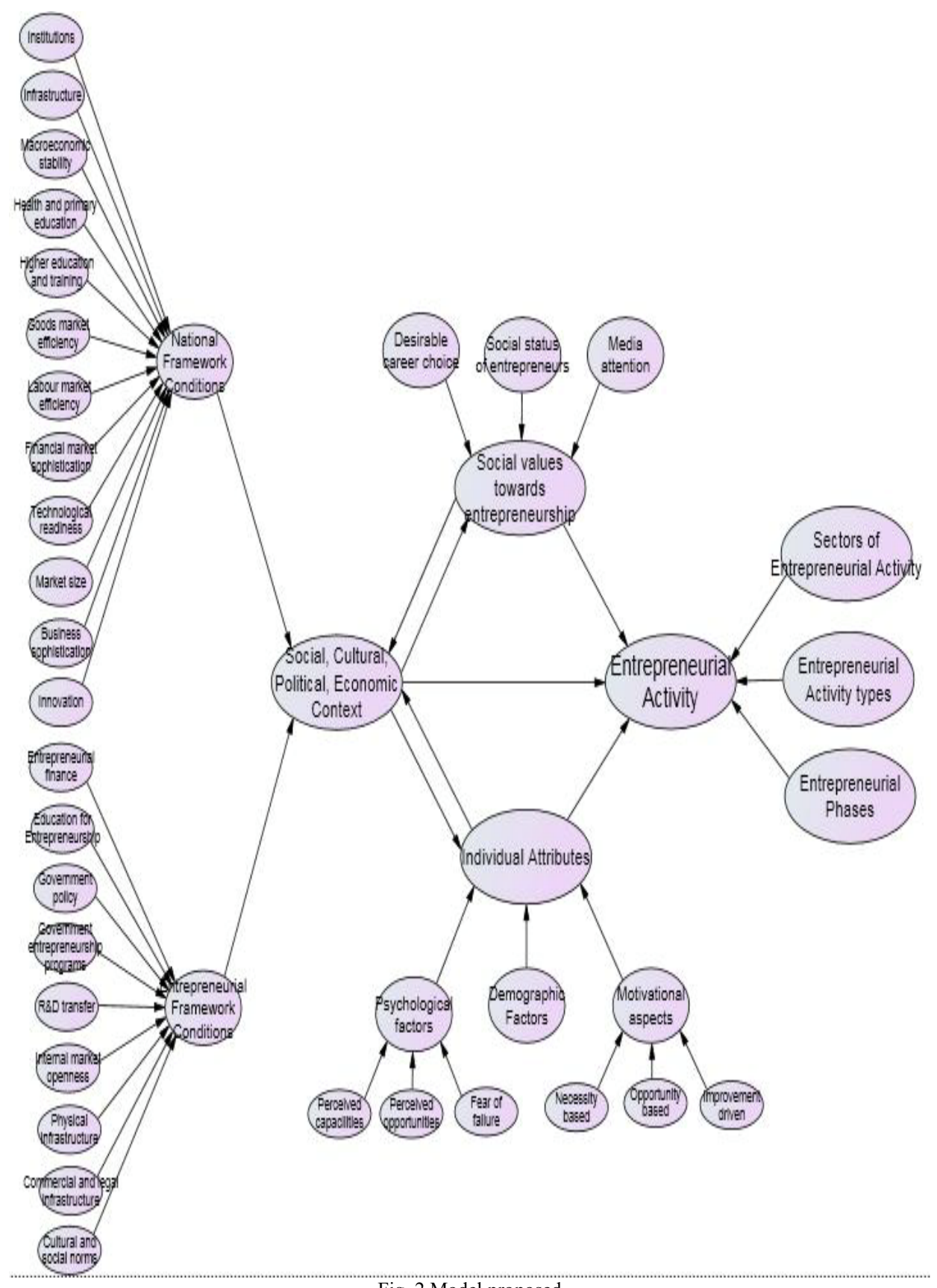

Fig. 2 Model proposed

\section{METHODOLOGY}

The research strategy used was data collection through questionnaires, which are usually associated with deductive approach. For the statistical test, the GEMCF, observable and quantitative data about perceptions of entrepreneurs was required. The data collected had to be standardized, in order to make it comparable.
Several entrepreneurial networks in the Madrid region were contacted, like Fundación Madri+d, Tetuán Valley and Actúa UPM, for data collection.

Once the data had been collected, a statistical analysis was performed, which was composed by three stages: Exploratory Factor Analysis (EFA), Confirmatory Factor Analysis (CFA) and Structural Equation Modelling (SEM). Two statistical packages were used: SPSS (for EFA) and AMOS (for CFA and SEM). A total of 18 variables were extracted from the survey, as summarized in Table 1.

$17^{\text {th }}$ LACCEI International Multi-Conference for Engineering, Education, and Technology: "Industry, Innovation, And Infrastructure for Sustainable Cities and Communities", 24-26 July 2019, Jamaica. 
Table 1 List of variables

\begin{tabular}{ll}
\hline Variables & Variables \\
\hline Level of education (LEl) & Family desirability (FD) \\
$\begin{array}{l}\text { Influence of education on entrepreneurial } \\
\text { intention (IEEI) }\end{array}$ & Couple desirability (FD) \\
Influence of education on type of & Friends desirability (RD) \\
entrepreneurial activity (IETEA) & \\
Applied-technology education (ATE) & Colleagues desirability (OD) \\
Entrepreneurial education (EE) & Society desirability (SD) \\
Direct role models (DRM) & Perceived capabilities - Easiness (PCE) \\
Indirect role models (IRM) & Perceived capabilities - Control (PCC) \\
Preference for entrepreneurship (PFE) & Age group (A) \\
Entrepreneurship as an attractive future (EAF) & Improvement-driven motivation (IDM)
\end{tabular}

The CFA allowed reducing these 18 variables to 4 latent variables, namely (1) "Influence of higher education and training", (2) "Influence of perceived capabilities and desirability", (3) "Influence of role models" and (4) "Influence of social perceived desirability", which are thoroughly described in the next section.

To answer the research question mentioned above, attention is paid to the GEM Conceptual Framework (see Fig. 1) and to the existing literature, as detailed in the following.

First, the existence of human capital is known to be crucial for the entrepreneurial process [18]. Education is one of the main assets of human capital, and in this vein, the exposure to entrepreneurship training has been noted to foster entrepreneurial intention [19]. Meta-analyses show that entrepreneurial education is positively linked with entrepreneurial outcomes [20] and with entrepreneurial intentions [21]. Hence, a first hypothesis is proposed, namely,

H1a. The component "Higher education and training" has a positive influence on "Entrepreneurial Activity".

Second, social perceived desirability has been noted as of the perceptions that allow for entrepreneurship intention [19]. Both desirability and perceived capabilities are strongly influenced by the exposure to role models [7]. On the one hand, parental role models, both positive and negative, have been found on the literature $[8,9,22]$, and on the other, knowing personally an entrepreneur [23]. Therefore, the following two hypotheses have been developed:

H1b. The component "Desirable career choice" has a positive influence on "Entrepreneurial Activity".

H1c. The determinant "Perceived capabilities" has a positive influence on "Entrepreneurial Activity".

Last, former concepts are strongly interlinked, and for this reason, the following three hypotheses will also be tested:

$\mathrm{H} 2 \mathrm{a}$. There is a positive correlation between "Higher education and training" and "Desirable career choice".
$\mathrm{H} 2 \mathrm{~b}$. There is a positive correlation between "Desirable career choice" and "Perceived capabilities".

$\mathrm{H} 2 \mathrm{c}$. There is a positive correlation between "Higher education and training" and "Perceived capabilities".

\section{RESULTS}

From 156 respondents, only 15 did not meet the requirement of having a technology-based venture in Spain and were eliminated from the sample. Hence, final sample comprised 141 entrepreneurs, of which $83.7 \%$ were men and $16.3 \%$ were women. Entrepreneurs' mean age was 35.4 years (standard deviation 8.5).

In terms of the highest education level completed, $17.7 \%$ had a $\mathrm{PhD}, 49.6 \%$ had Master's degree, $28.4 \%$ had a Bachelor's degree, $0.7 \%$ had Technical degree and 3.5\% was still finishing university. As expected, the most represented field in the sample was Engineering and Architecture. The least represented field was Arts and Human Studies.

Given the robustness of the statistical analyses used (both EFA and CFA), the CFA would have suggested the elimination of variables in order to obtain the same model.

Variables IEEI and IETEA were grouped in the same factor. They are related to the entrepreneur's perceived influence of his/her educational background in his/her entrepreneurial behaviour. This is closely related to the component "Higher education and training" of the GEMCF. This factor was named "Influence of Higher education and training" (IHET).

Variables LE1 and EE were grouped in the same factor. These variables are also related to the educational background of the respondent; however, they are not related to a perception but rather to a fact. This factor was called "Influence of higher education and training 2" (IHET2).

Variables DRM and IRM are related to the influence of role models on the entrepreneurial behaviour. Role Models are linked to the individual because they enhance self-efficacy [7], [24]. Thus, they are related to the component "Perceived capabilities" of the GEMCF. This factor was named "Influence of role models" (IRM2).

ATE and IDM are variables that apparently are not related to each other. However, as mentioned, two characteristics of high-growth potential entrepreneurship are improvement or opportunity-driven motivation and innovation. Applied technology is a clear way of innovation. This factor is related to the component "Motivational aspects" of the GEMCF, therefore it is named "Influence of innovation and motivation" (IIM).

PFE, EAF, PCE and PCC are variables related to the respondent's perception of the attractiveness of entrepreneurship and his/her capabilities and skills to become an entrepreneur. This factor is clearly linked to the component "Perceived capabilities" of the GEMCF. It was named "Influence of perceived capabilities and desirability" (IPCD).

$17^{\text {th }}$ LACCEI International Multi-Conference for Engineering, Education, and Technology: “Industry, Innovation, And Infrastructure for Sustainable Cities and Communities", 24-26 July 2019, Jamaica. 
FD, RD, OD and SD2 are variables related to the respondent's perception of whether society approves entrepreneurship. This factor is clearly linked to the component "Desirable career choice" of the GEMCF. It was named "Influence of social perceived desirability" (ISPD).

The research model on Fig. 3 was obtained after performing an EFA, firstly, CFA, secondly, and SEM, thirdly. It was improved by and tested against several statistics and criteria. As a result, all factor loadings were significant, except for the factor loadings on the variable Entrepreneurial Activity.

The first latent variable was "Influence of higher education and training" (IHET). This variable is measured the respondent's perception of the influence of his/her educational background on the entrepreneurial intention and the type of venture founded. The correspondent component in the GEMCF is "Higher education and training".

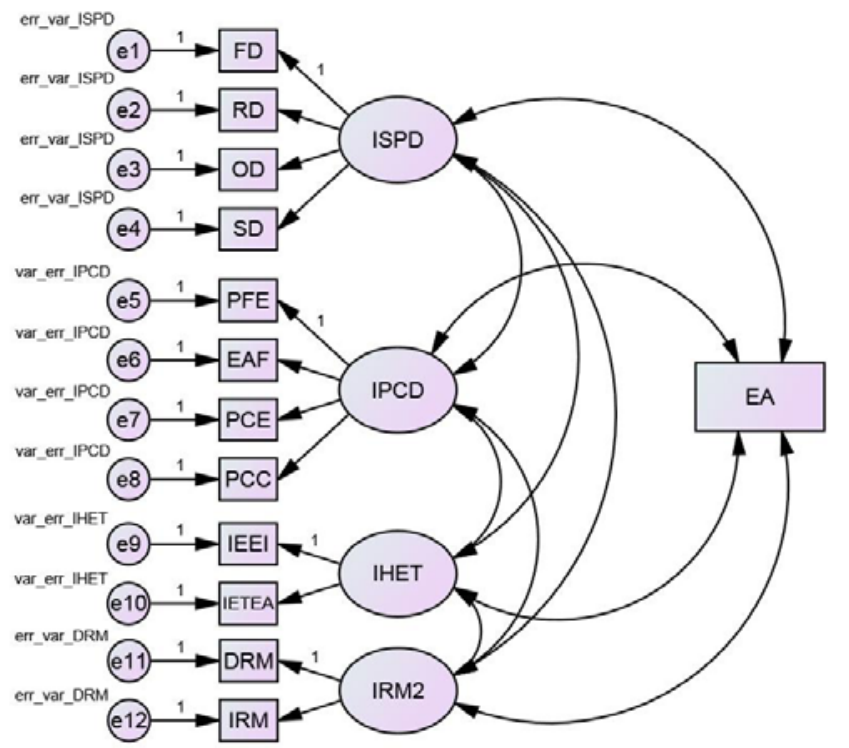

Fig. 3 Research model.

According to the World Economic Forum, this component measures "secondary and tertiary enrolment rates as well as the quality of education as evaluated by business leaders" [25]. It is also more "objective" parameters rather than perceptions, i.e. enrolment rates, level and quality of education.

The second latent variable used was "Influence of perceived capabilities and desirability" (IPCD): the respondent's perception about the attractiveness, preference and easiness of entrepreneurship and the ability to control the entrepreneurial process. The correspondent component of the GEMCF is "Perceived capabilities". According to the GEM, "Perceived capabilities" refers to the percentage of entrepreneurs "who believe they have the required skills and knowledge to start a business" [11].
The third latent variable used was "Influence of role models" (IRM2), i.e. the influence of direct (parents) and indirect (acquaintances) "entrepreneurial" role models. It has also been proposed as equivalent to the component of the GEMCF "Perceived capabilities". Indeed, the perception of skills and knowledge is enhanced by the presence of role models [24]. Furthermore, exposure to "entrepreneurial" role models predisposes an individual to become an entrepreneur [7].

Finally, the fourth latent variable used was "Influence of social perceived desirability" (ISPD). This variable measures the respondent's perception of whether society (including family, friends and colleagues) approves entrepreneurship or not. The correspondent GEMCF component is "Desirable career choice". For the GEM project, this component measures the extent to which "starting a new business is a desirable career choice" [11].

Consequently, the chosen latent variables accurately reflect the correspondent components of the GEMCF.

Table 2 Model Fit Indices

\begin{tabular}{lll}
\hline Model Fit Index & Model & Objective \\
\hline Chi-square value (CMIN) & 78.455 & 0 \\
Probability & 0.106 & 1 \\
DoF & 64 & As large as possible \\
CFI & 0.878 & 1 \\
GFI & 0.914 & 1 \\
NFI & 0.601 & 1 \\
RMSEA & 0.04 & $<0.05$ \\
\hline
\end{tabular}

In accordance with Table 2, the model is accepted.

The results obtained were satisfactory. They are aligned to what is proposed in the GEMCF and other behaviour-based models of entrepreneurship.

Hypotheses H1a, H1b and H1c were accepted. The components "Higher education and training", "Desirable career choice" and "Perceived capabilities" measured through variables "Influence of Higher education and training", "Influence of social perceived desirability" and "Influence of perceived capabilities and desirability", had a positive influence on the variable "Entrepreneurial Activity" (standardized factor loadings $=0.343,0.057$ and 0.054, respectively). However, the variable "Influence of role models" had a negative influence on "Entrepreneurial Activity" (factor loading $=-0.230$ ). This influence was not expected.

\section{CONCLUSIONS}

$17^{\text {th }}$ LACCEI International Multi-Conference for Engineering, Education, and Technology: "Industry, Innovation, And Infrastructure for Sustainable Cities and Communities", 24-26 July 2019, Jamaica. 
Understanding entrepreneurial behaviours is basic for public institutions that aim to foster them. A reference model for entrepreneurial behaviours is the Conceptual Framework provided by GEM. In this study, the robustness of this framework is checked for a particular context: New Technology-Based Firms from Spain. To that end, a questionnaire has been developed; a sample of 157 entrepreneurs has been gathered, and analysed through Exploratory Factor Analysis, Confirmatory Factor Analysis and Structural Equation Modelling.

The results obtained were satisfactory. They are aligned to what is proposed in the GEMCF. In fact, all the hypotheses of the study were accepted. They indicated the fundamental relationships of the components of the GEMCF: correlations among components, and causal relationships between components and the entrepreneurial activity.

A theoretical behaviour-based model of entrepreneurship can be empirically tested through perceptions of entrepreneurs regarding the influence of certain components in their intention and behaviour. In this study, by following the abovementioned procedure, relevant findings were obtained, consistent with the literature: the model presented positive correlations among higher education and training, the society desirability of entrepreneurship and the individual attributes of the entrepreneur. These components were positively related to the entrepreneurial activity, especially higher education and training, which had a significant influence on entrepreneurship.

One interesting issue regarding the estimated factor loadings is that the only significant loading was IHET on EFA. The sample chosen comprised new technology-based firms (NTBF). The importance of education in NTBF is crucial [7].

Finally, this research raises the question: are the determinants "Society values towards entrepreneurship" and "Individual Attributes" positively correlated? The GEMCF does not include a correlation among these. Our findings suggest that there might exist a correlation between both determinants, which is important because of its potential social implications.

Normally, the enhancement of individual attributes is usually achieved through government involvement, particularly in education and public policies. However, media attention could also influence the individual attributes. For example, by documenting and exposing successful entrepreneurs or public policies that encourages entrepreneurship, media can impact the perceived opportunities of an individual. If successful entrepreneurs enjoy a high level of status and respect in the society, other individuals might be influenced to become entrepreneurs, motivated to achieve a high status in society.

For further research the GEMCF proposes a total of 31 components, which can be measured through countless observed variables. If resources are available, more variables should be included in the model to improve its statistical fit and its ability to explain entrepreneurship. This could be done through interviews to experts, to obtain qualitative data and propose observed variables based not only on intuition but also on the opinion of an expert.

Besides that, the sample mix should be more diverse in terms of age and entrepreneurial activity. Particularly, individuals that are not entrepreneurs should be included in the analysis, in order to increase the correlation among the variables that explain entrepreneurship and obtain statistically significant measures.

Finally, normality and linearity issues must be addressed to properly fit the model to the data collected. Robust Maximum Likelihood estimation or data normalization are valid techniques to deal with non-normalized data. In case of linearity issues, the application of nonlinear transformation of data or similar techniques should be considered. This should assure, firstly, that correlation among variables favours Exploratory and Confirmatory Factor Analyses, and secondly, that the assumption of linearity and normality is met. By doing so, Maximum Likelihood method can be used in the estimation of the data correlation matrix, which leads to obtain asymptotic conclusions, i.e. conclusions that are approximately true for large samples.

\section{ACKNOWLEDGMENT}

The invaluable help and support for the data collection of this study of start-up incubators Fundación Madri+d, Tetuán Valley and Actúa UPM is heartfully acknowledged. Likewise, the stipend provided by the European Commission to the first author of the paper is gratefully appreciated.

\section{REFERENCES}

[1] M. Porter, (1990) The competitive advantage of nations. New York: The Free Press.

[2] S. Blank, \& B. Dorf, (2012). The startup owner's manual: The stepby-step guide for building a great company.

[3] C.M. Beckman, K. Eisenhardt, S. Kotha, A. Meyer, and N. Rajagopalan, (2012). The role of the entrepreneur in technology entrepreneurship. Strategic Entrepreneurship Journal, 6(3), 203-206.

[4] F. Liñán, \& Y. Chen, (2009). Development and cross-cultural application of a specific instrument to measure entrepreneurial intentions. Entrepreneurship: Theory and Practice, 33(2), 593-618. http://dx.doi.org/10.1111/j.1540-6520.2009.00318.x.

[5] J. C. Hayton, G. George, and S. A. Zahra, (2002) 'National Culture and', 26.

[6] I. Ajzen, (1991). The theory of planned behavior. Organizational Behavior and Human Decision Processes, 50, 179-211. http://dx.doi.org/10.1016/0749-5978(91)90020-T.

[7] I. Pablo-Lerchundi, G. Morales-Alonso, and R. M. González-Tirados, (2015) 'Influences of parental occupation on occupational choices and professional values', Journal of Business Research. Elsevier Inc. doi: 10.1016/j.jbusres.2015.02.011.

[8] G. Morales-Alonso, I. Pablo-Lerchundi, and A. M. Vargas-Perez, (2016) 'An Empirical Study on the Antecedents of Knowledge Intensive Entrepreneurship', International Journal of Innovation and Technology Management, 13(5). doi: 10.1142/S0219877016400113.

[9] G. Morales-Alonso, I. Pablo -Lerchundi, and M.-C. Núñez-Del-Río, (2016) 'Entrepreneurial intention of engineering students and associated influence of contextual factors / Intención emprendedora de

$17^{\text {th }}$ LACCEI International Multi-Conference for Engineering, Education, and Technology: "Industry, Innovation, And Infrastructure for Sustainable Cities and Communities", 24-26 July 2019, Jamaica. 
los estudiantes de ingeniería e influencia de factores contextuales', Revista de Psicologia Social, 31(1). doi: 10.1080/02134748.2015.1101314.

[10] S. Shane, (2009) 'Why encouraging more people to become entrepreneurs is bad public policy', Small Business Economics, 33(2), pp. 141-149. doi: 10.1007/s11187-009-9215-5.

[11] Singer, S., Amorós, J. E. and Moska, D. (2015) GEM 2014 Global Report. Babson Park, USA: Babson College.

[12] E. Congregado, A. A. Golpe, \& M. Carmona, (2010). Is it a good policy to promote self-employment for job creation? Evidence from Spain. Journal of Policy Modeling, 32(6), 828-842. http://doi.org/10.1016/i.jpolmod.2010.09.001

[13] R. Fairlie, (2013). Entrepreneurship, economic conditions, and the great recession. Journal of Economics \& Management Strategy, 46. Retrieved http://onlinelibrary.wiley.com/doi/10.1111/jems.12017/full

[14] M.-J. Pinillos, \& L. Reyes, (2011). Relationship between individualist-collectivist culture and entrepreneurial activity: evidence from Global Entrepreneurship Monitor data. Small Business Economics, 37(1), 23-37. http://doi.org/10.1007/s11187-009-9230-6

[15] R. S. Shinnar, O. Giacomin, \& F. Janssen, (2012). Entrepreneurial Perceptions and Intentions: The Role of Gender and Culture. Entrepreneurship Theory and Practice, 36(3), 465-493. http://doi.org/10.1111/j.1540-6520.2012.00509.x

[16] P. K. Wong, Y. P. Ho, \& E. Autio, (2005). Entrepreneurship, Innovation and Economic Growth: Evidence from GEM data. Small Business Economics, 24(3), 335-350. http://doi.org/10.1007/s11187$\underline{005-2000-1}$

[17] S. Wennekers, R. Thurik, A., Van Stel, \& N. Noorderhaven, (2007). Uncertainty Avoidance and the Rate of Business Ownership across 21 OECD Countries, 1976-2004. Journal of Evolutionary Economics, 17(2), 133-160.

[18] M. G. Colombo, and L. Grilli, (2010) On growth drivers of high-tech start-ups: Exploring the role of founders' human capital and venture capital, Journal of Business Venturing. Elsevier Inc., 25(6), pp. 610 626. doi: 10.1016/j.jbusvent.2009.01.005

[19] F. Liñán, J. C. Rodríguez-Cohard, and J. M. Rueda-Cantuche, (2011) Factors affecting entrepreneurial intention levels: A role for education, International Entrepreneurship and Management Journal, 7(2), pp. 195-218. doi: 10.1007/s11365-010-0154-z.

[20] B. C. Martin, J. J. McNally, M. J. and Kay, (2013) Examining the formation of human capital in entrepreneurship: A meta-analysis of entrepreneurship education outcomes, Journal of Business Venturing. Elsevier Inc., 28(2), pp. 211-224. doi: 10.1016/j.jbusvent.2012.03.002.

[21] T. J. Bae, . S. Qian, C. Miao, J. O. Fiet. (2014) The Relationship Between Entrepreneurship Education and Entrepreneurial Intentions: A Meta-Analytic Review, Entrepreneurship: Theory and Practice, 38(2), pp. 217-254. doi: 10.1111/etap.12095.

[22] M. Bloemen-Bekx, W. Voordeckers, C. Remery, J. Schippers, (2019) Following in parental footsteps? The influence of gender and learning experiences on entrepreneurial intentions, International Small Business Journal: Researching Entrepreneurship. doi: $10.1177 / 0266242619838936$.

[23] V. Martin-Sanchez, I. Contín-Pilart, and M. Larraza-Kintana, (2018) The influence of entrepreneurs' social referents on start-up size, International Entrepreneurship and Management Journal. International Entrepreneurship and Management Journal, 14(1), pp. 173-194. doi: 10.1007/s11365-017-0454-7.

[24] P. Arenius, and M. Minniti, (2005) 'Perceptual Variables and Nascent Entrepreneurship', Small Business Economics, 24(3), pp. 233-247. doi: 10.1007/s11187-005-1984-x.

[25] World Economic Forum (2018) The Global Competitiveness Report 2017-2018, Geneva. Available at http://www3.weforum.org/docs/GCR2017-

2018/05FullReport/TheGlobalCompetitivenessReport2017-2018.pdf (Accessed: 3 March 2018)

$17^{\text {th }}$ LACCEI International Multi-Conference for Engineering, Education, and Technology: "Industry, Innovation, And Infrastructure for Sustainable Cities and Communities”, 24-26 July 2019, Jamaica. 